(RESEARCH ARTICLE)

\title{
Prevalence, intensity and some vector dynamics of malaria in Ogbaru local government area of Anambara State, Nigeria
}

Dike-Ndudim Joy Nkeiruka 1, ${ }^{*}$, Udujih Helen Ifeoma 1, Anikwo Emeka Simon 2, Amah Henry Chidozie 1, Okorie Hope Mercy ${ }^{1}$, Udujih Obinna Godwin ${ }^{3}$, Obikwelu Emmanuel ${ }^{4}$, Opara Ambrose Uche ${ }^{1}$, Nwosu Dennis Chimezie ${ }^{1}$ and Nwanjo Harrison Ugo ${ }^{1}$

${ }^{1}$ Department of Medical Laboratory Science, Faculty of Health Science, Imo State University Owerri, Imo State, Nigeria

${ }^{2}$ Department of Human Physiology, Faculty of Basic Medical Sciences, Imo State University Owerri, Imo State, Nigeria.

${ }^{3}$ Department of Public Health, School of Health Technology, Federal University of Technology Owerri, Imo Sate, Nigeria

${ }^{4}$ Department of Neglected Tropical Diseases, Anambra State Ministry of Health, Nigeria.

Publication history: Received on 07 October 2020; revised on 22 October 2020; accepted on 25 October 2020

Article DOI: https://doi.org/10.30574/wjarr.2020.8.2.0374

\begin{abstract}
A study on the prevalence, intensity and some vector dynamics of malaria was carried out in Ogbaru Local Government Area of Anambra State using standard parasitological and entomological techniques for rapid assessment of malaria infection, level of parasitaemia and morphological features of mosquitoes. The results showed an overall malaria RDT prevalence of $20 \%$ and community based prevalence of $13(16.0 \%)$ and 22(24\%) for Odekpe and Ogbakuba respectively. In Odekpe, the age range (1-7 years) had the highest prevalence while in Ogbakuba the highest prevalence was the age range 7-14 years. Overall, males had lower malaria prevalence $(14.0 \%)$ than females $(21.0 \%)$. The intensity of malaria infection from each of the communities revealed that both high $(>2000-250000$ parasites $/ \mu \mathrm{l})$ and medium (>500-2000 parasites/ $\mu \mathrm{l}$ ) parasitaemia was more in Ogbakuba community. Two hundred and thirty (230) mosquitoes were collected. One hundred and four (45\%) of the total mosquito population in the study were found to be unfed with blood meal, whereas $86(37 \%)$ and $40(17 \%)$ were freshly and previously fed respectively. One hundred and forty two $(61.7 \%)$ of the mosquitoes appeared gravid against $88(38 \%)$ that were non-gravid. The mosquitoes encountered were Anopheles gambiae 76(33.04\%), Anopheles funestus 86(37.39\%), and Culex specie 68(29.56\%). Malaria transmission and possibility of an ongoing transmission of other mosquito-borne diseases among residents in the study area should necessitate design for further studies that would explore the interactions of mosquito species and the diseases they transmit in co- endemic communities as well as effective methods for their control.
\end{abstract}

Keywords: Malaria; Nigeria; Vector dynamics; Mosquito-borne diseases; Filariasis

\section{Introduction}

Malaria infection is largely distributed throughout warmer regions of the world, especially in the tropics where the vectors of malaria are found in large numbers. Farming activities which take place mostly during the rainy season of the year favour the breeding of mosquitoes and this makes the effects of malaria apparently noticeable in rural areas due to their proximity to farmlands [1]. In rural areas of Africa such as Anambra State Nigeria, malaria infection is quite endemic and younger children are most susceptible due to low immunity and poor hygiene. In Nigeria, malaria is holoendemic and it is one of the reasons for high mortality rates in children [2].

\footnotetext{
* Corresponding author: Dike-Ndudim Joy Nkeiruka, phone: +2348037922835, E-mail: divinejoyd@yahoo.com Department of Medical Laboratory Science, Faculty of Health Science, Imo State University Owerri, Imo State, Nigeria. 
Malaria is one of the most important public health problems in the world with Nigeria accounting for the greatest number of cases and deaths among all the countries in the world [3], United States Embassy in Nigeria, 2016. Nigeria malaria fact Sheet (Online) Available at: <http://nigeria.usembassy.gov (Accessed 12 march, 2019).

It is a disease of humans and animals caused by protozoan parasites of the genus Plasmodium [4, 5]. In humans, malaria is caused by P. falciparium, P. Malariae, P. ovale and P. vivax with P. falciparium as the most common cause of human infection responsible for about $90 \%$ of deaths [6]. The female mosquitoes of the Anopheles genus serve as the primary hosts and transmission vectors of the parasites. Malaria is endemic throughout most of the tropical countries with an ongoing transmission in 95\% countries and territories according to World Health Organization, 2015. Fact Sheet: malaria World Report (online) Available at: <www.int/malaria/world malaria report (Accessed March 15, 2019).

In Nigeria, the degree of malaria infection varies from region to region [7]. Transmission rate in the Southern region is approximately uniform throughout the year where it is holoendemic in the rural area and mesoendemic in the urban areas [8].

There are an estimated 100 million malaria cases with over 300,000 deaths per year in Nigeria, compared with 215,000 deaths per year in Nigeria as a result of HIV/AIDS [United States Embassy in Nigeria, 2016. Nigeria malaria fact Sheet. (Online) Available at: <http://nigeria.usembassy.gov (Accessed 12 march, 2019)]. Due to the nocturnal feeding habits of most Anopheles mosquitoes, malaria transmission occurs primarily at night. Protection of man against mosquito bite include: the use of mosquito bed nets (preferably insecticide-treated nets (ITNs), and use of insect repellent on exposed skin [European Centre for Disease prevention and Control (ECDC) available at: <http://ecdc.evropa.eu (Accessed 15 March, 2019)]. Past and present malaria control programmes as well as the most recent Malaria Control Programme Plan achieved limited success on eradicating the scourge. In spite of this, the malaria situation has steadily worsened and currently it is estimated that malaria accounts for $65 \%$ of all diseases reported in Nigerian health facilities and that $42 \%$ of pregnant women are diagnosed with malaria which affects the birth weight of infants. Moreover, it is estimated that at least one million people die of malaria each year, mostly children under five years and more than $80 \%$ of the deaths worldwide occur in Sub Saharan Africa [9].

The use of insecticide-treated mosquito nets is a primary health intervention designed to reduce malaria transmission in Nigeria [10]. Accordingly, out of the total 663 million malaria cases averted in the past 15years in SSA, 67-73\% has been attributed to the extensive distribution and use of ITNs [11], World Health Organization, [2015] Fact Sheet: malaria World Report (online) Available at: <www.int/malaria/world malaria report (Accessed March 15, 2019)]. However, despite massive scale-up of ITN distribution in Sub-Saharan Africa, shortfalls and inequalities exist [12] which compromise long-term elimination or control programs. Low socio-economic status is associated with low uptake and use of ITNs [13]. Although many health ministries and non-governmental organizations (NGOs) widely distribute ITNs for free or at low cost, their incorrect and inconsistent use remains problematic. Pyrethroids are the only insecticide class approved for use on ITNs [11] and resistance to pyrethroid insecticides in Anopheles malarial mosquito vectors is now widespread throughout Sub-Saharan Africa [14].

\section{Material and methods}

\subsection{Study Area}

The study was carried out in Ogbaru Local Government Area (LGA) in Anambra State. A total of 2 communities (Odekpe and Ogbakuba) were selected for the study. These communities selected are currently under the Neglected Tropical Diseases (NTDs) elimination programme [15].

The study communities lie within the humid tropical rainforest belt of south eastern Nigeria. The main occupation of the people is fishing, subsistence farming and trading. The nature of their occupation predisposes them to frequent mosquito bites.

\subsection{Ethical Considerations}

An advocacy visit was made to the traditional heads of the selected communities for mobilization and support. Letter of intent was sent to the stake holders in the selected communities. Ethical approval was obtained from the State Ministry of Health, Anambra State.

\subsection{Study design}


This involved malaria cross sectional survey of 174 randomly recruited subjects (75 males and 99 females) from age 1 year and above using rapid diagnostic test kits for P. falciparum, thick and thin films. A pre-tested questionnaire was used to obtain demographic information.

\subsection{Sample Collection and Examination}

Two sets of $20 \mu \mathrm{l}$ of capillary blood were collected from the middle finger using a capillary tube. Ten micro litres of blood each was dropped on SD Bioline immune-chromatographic test kits for P. falciparum Ag HRP2 antigen. Two micro litres of blood were dropped on the outer end of the slide for thin film making, while six micro litres were used to make a thick film on the inner part of the slide. The thin film was fixed in $70 \%$ methanol. All blood films were stained using $3 \%$ Giemsa stain for 30 minutes [16].

The stained slides were sent to the laboratory to be viewed microscopically for malaria parasite detection, speciation and parasite count. The films were counted by using a four digit hand tally counter and Olympus microscope.

Parasite density was calculated and reported according to World Health Organization, [2015] Fact Sheet: malaria World Report (online) Available at: <www.int/malaria/world malaria report (Accessed March 15, 2019), with little modification in grading as; low (50-500 parasites/ $\mu$ l), medium $(>500-2000$ parasites/ $\mu$ l) and high $(>2000-250,000$ parasites/ $\mu \mathrm{l}$ ) using the formula:

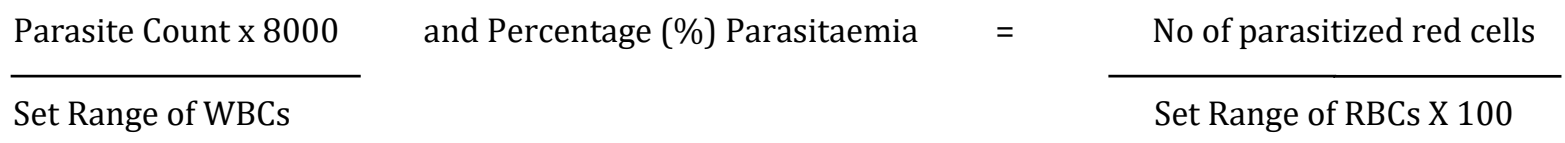

A total of eighty (80) rooms were selected for mosquito knock down in this study. All the compounds in each community were numbered and twenty (20) compounds out of the even numbered compounds were selected systematically. In each of the chosen compounds, the room where the highest number of persons slept was selected. Out of the eighty rooms selected for knock down, forty were from houses with block walls, ceiling and closed eaves, whereas the other forty were from those with open eaves with or without ceiling. The former was designated improved houses, while the later was named unimproved houses. Each group was further divided into those that use ITBN and those that use window net as vector control measure.

Indoor resting mosquitoes were sampled between 06:00am and 10:00am using pyrethrum spray catches (PSC) method [17]. In each room, a pyrethrum insecticide was sprayed into the space with window and doors closed; mosquito collection was made after about 10 minutes on a white cloth following knock-down. Mosquitoes were identified using morphological key of Gilles and De Miller [18] and counted, noting their physiological stages [19].

\section{Results}

Overall, Ogbaru LGA recorded a malaria prevalence of $20.10 \%$ (35) out of the 174 subjects tested. The number of individuals tested for malaria in Ogbakuba community were 91(33.2\%), -- of which 22(39\%) were positive, resulting in local prevalence of $24.4 \%$. Eighty-three (30.3\%) individuals were tested in Odekpe community and 13(23\%) were positive, giving $16 \%$ local malaria prevalence (Table 1).

Table 1 Overall RDT (Rapid Diagnostic Test) prevalence of malaria in the study population

\begin{tabular}{|l|l|l|l|}
\hline Community & No. tested & No. positive & Prevalence (\%) \\
\hline Odekpe & $83(30.3 \%)$ & $13(23 \%)$ & 16.0 \\
\hline Ogbakuba & $91(33.2 \%)$ & $22(39 \%)$ & 24.2 \\
\hline Total & 174 & 35 & 20.1 \\
\hline
\end{tabular}

Overall sex related prevalence in Ogbaru LGA showed that males had lower malaria prevalence (14.0\%) than females (21.0\%). 
In Odekpe community (table 2), 36(43\%) males were tested and 5 turned positive giving a prevalence of 38\%. The prevalence was $62 \%$ for the females, where 8 tested positive out of 39 individuals.

Out of the 91 individuals tested in Ogbakuba, 39(43\%) were males while 52(57\%) were females; $9(38 \%)$ and 13(59\%) were positive respectively (Table 3)

Table 2 Sex related malaria prevalence in Odekpe Community

\begin{tabular}{|l|l|l|l|l|}
\hline Sex & $\begin{array}{l}\text { Number } \\
\text { tested }\end{array}$ & $\begin{array}{l}\text { Number } \\
\text { negative }\end{array}$ & $\begin{array}{l}\text { Number } \\
\text { positive }\end{array}$ & Prevalence (\%) \\
\hline Male & $36(43 \%)$ & 31 & 5.0 & 38 \\
\hline Female & $47(57 \%)$ & 39 & 8.0 & 62 \\
\hline Total & 83 & 70 & 13 & 100 \\
\hline
\end{tabular}

Table 3 Sex Related Malaria Prevalence in Ogbakuba Community

\begin{tabular}{|l|l|l|l|l|}
\hline Sex & $\begin{array}{l}\text { Number } \\
\text { tested }\end{array}$ & $\begin{array}{l}\text { Number } \\
\text { negative }\end{array}$ & $\begin{array}{l}\text { Number } \\
\text { positive }\end{array}$ & Prevalence (\%) \\
\hline Male & $39(43 \%)$ & 30 & 9 & 41 \\
\hline Female & $52(57 \%)$ & 39 & 13 & 59 \\
\hline Total & 91 & 69 & 22 & 100 \\
\hline
\end{tabular}

In Odekpe community, the highest malaria prevalence was also seen among those aged between 1 to 7 years (table 4); out of 83 individuals tested in the community, 27 were of this age bracket and 4 tested positive giving a prevalence of $30 \%$. This was followed by those between 7 to 14 years and 14 to 21 years, where 17 and 6 individuals were tested respectively with 3 turning positive in each group, resulting in the same prevalence of $23 \%$ each. A prevalence of $8 \%$ was recorded in age groups 28 to 35, 35 to 42, 42 and above, their sample sizes being 6, 4 and 9 respectively. Out of the 14 individuals tested in age group 21 to 28 years, none tested positive. (Table 4).

Table 4 Age Related Prevalence of Malaria in Odekpe Community

\begin{tabular}{l|l|l|l|}
\hline \multicolumn{1}{l}{ Age range (years) } & \multicolumn{1}{l}{ No. tested } & \multicolumn{2}{l}{ No. positive } \\
\hline $1-7$ & 27 & 4 & 30 \\
\hline $7-14$ & 17 & 3 & 23 \\
\hline $14-21$ & 6 & 3 & 23 \\
\hline $21-28$ & 14 & 0 & 0 \\
\hline $28-35$ & 6 & 1 & 8 \\
\hline $35-42$ & 4 & 1 & 8 \\
\hline 42 and above & 9 & 1 & 8 \\
\hline Total & 83 & 13 & 16 \\
\hline
\end{tabular}

A total of 91 individuals were tested in Ogbakuba community. The highest number tested, 22 were among age group 1 to 7 , with 7 individuals testing positive (31\%). The highest age-related prevalence (36\%) was among age group 7 to 14 years, where 8 out of 16 subjects tested positive. Seventeen (17) individuals were tested among those aged 42 years and above and 4 tested positive (18\%). A prevalence of 5\% was recorded among age groups 14 to 21,21 to 28 and 28 to 35. All the 11 people tested among age group 35 to 42 years were negative (Table 5). 
Overall, age related prevalence in the LGA showed that the age bracket 1 to 7 years had the highest malaria prevalence (61.0\%), followed by the age range 7-14 years (59.0\%), while subjects in the age bracket 21-28 had the least (5.0\%).

Table 5 Age Related Malaria Prevalence in Ogbakuba Community

\begin{tabular}{|c|c|c|c|}
\hline Age range (years) & No. tested & No. positive & Prevalence \\
\hline $1-7$ & 22 & 7 & 31 \\
\hline $7-14$ & 16 & 8 & 36 \\
\hline $14-21$ & 10 & 1 & 5 \\
\hline $21-28$ & 9 & 1 & 5 \\
\hline $28-35$ & 6 & 1 & 5 \\
\hline $35-42$ & 11 & 0 & 0 \\
\hline 42 and above & 17 & 4 & 18 \\
\hline Total & 91 & 22 & 24 \\
\hline
\end{tabular}

The intensity of malaria infection from each of the communities (figure 1) revealed that both high and medium parasitaemia were more in Ogbakuba community. Odekpe recorded lower intensity of malaria parasitaemia.

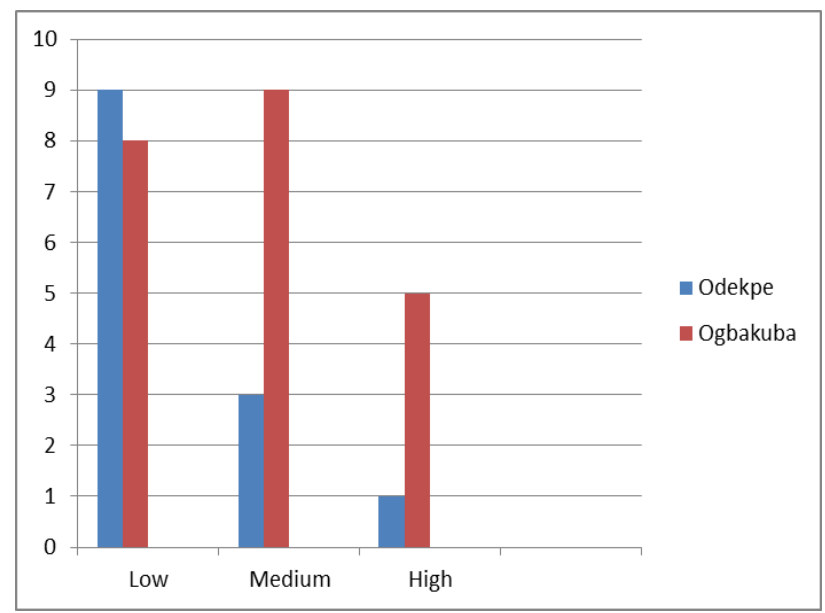

Figure 1 Intensity of Plamodium parasitaemia across the two Communities in the study

A total of two hundred and thirty mosquitoes were collected from both communities. In Odekpe, 38(35\%) were Anopheles funestus, 40(37\%) Anopheles gambiae sl and 31(28\%) were of the Culex Species. The unfed population were more of the Culex (41.5\%), followed by Anopheles gambiae sl (34\%) and Anopheles funestus(24.5\%). Forty-three percent (43\%) of those that had fresh blood meal were Anopheles funestus, followed by Anopheles gambiae sl (37\%) and Culex (20\%), while Anohpeles gambiae sl had the highest number (41\%) of those that had blood meal previously, followed by Anopheles funestus (35\%) and the Culex (24\%). Among the gravid mosquitoes identified in Odekpe community, 38\% were Anopheles gambiae sl, 37\% Anopheles funestus and 25\% were Culex as against 33.3\%, 30.3\% and 36.4\% respectively for those that are non-gravid. Generally, Odekpe community recorded 41(38\%) unfed mosquitoes, $51(47 \%)$ freshly fed, 17(15\%) previously fed, 76(70\%) gravid and 33(30\%) non-gravid (Figure 2).

Ogbakuba community recorded a total of 121 mosquitoes. The physical features of mosquitoes identified in Ogbakuba community showed that Anopheles funestus formed 38\% of those that were unfed, followed by 33\% Anopheles gambiae sl and 29\% Culex species. Among those that were freshly fed, 43\% were Anopheles funestus, 34\% Culex and 23\% Anopheles gambiae sl, while $40 \%$ of those that appeared previously fed were Anopheles funestus, followed by Anopheles gambiae and Culex Species which were 30\% each. Forty four percent (44\%) of the gravid mosquitoes caught in the area were Anopheles funestus, 32\% Culex and 24\% Anopheles gambiae sl, while the non-gravid were 36\% (Anopheles gambiae sl), 35\% (Anopheles funestus) and 29\% (Culex species). Ogbakuba in summary recorded 63(52\%) unfed mosquitoes, $35(29 \%)$ freshly fed and 23(19\%) previously fed, with 66(55\%) gravid and 55(45\%) non-gravid (Figure 3). 


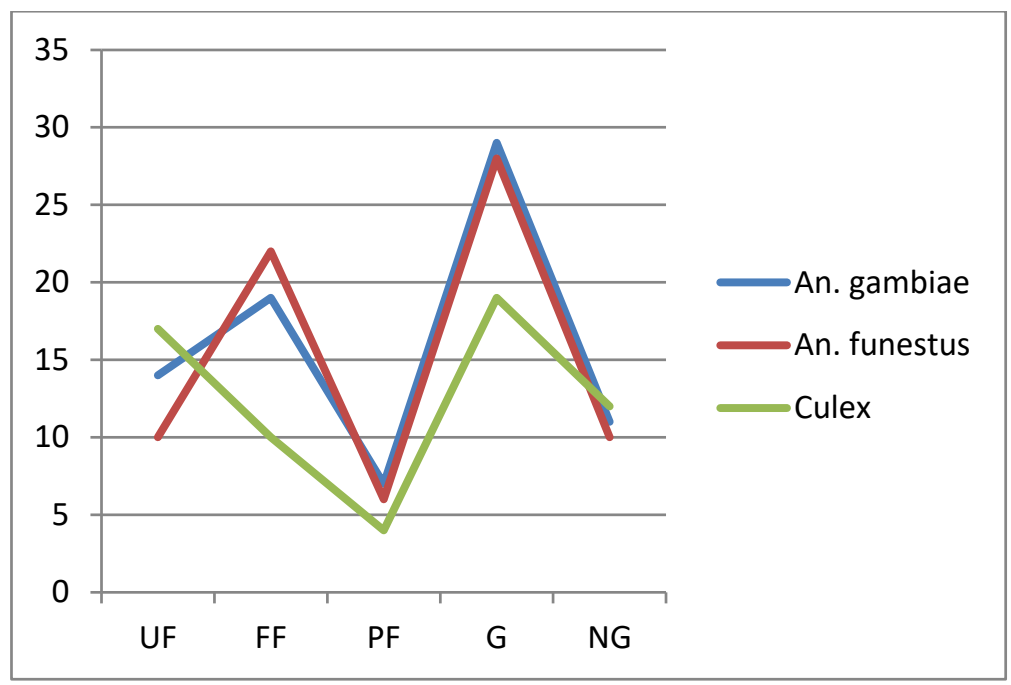

Figure 2 Physical Characteristics of Mosquito Species Identified In Odekpe Community

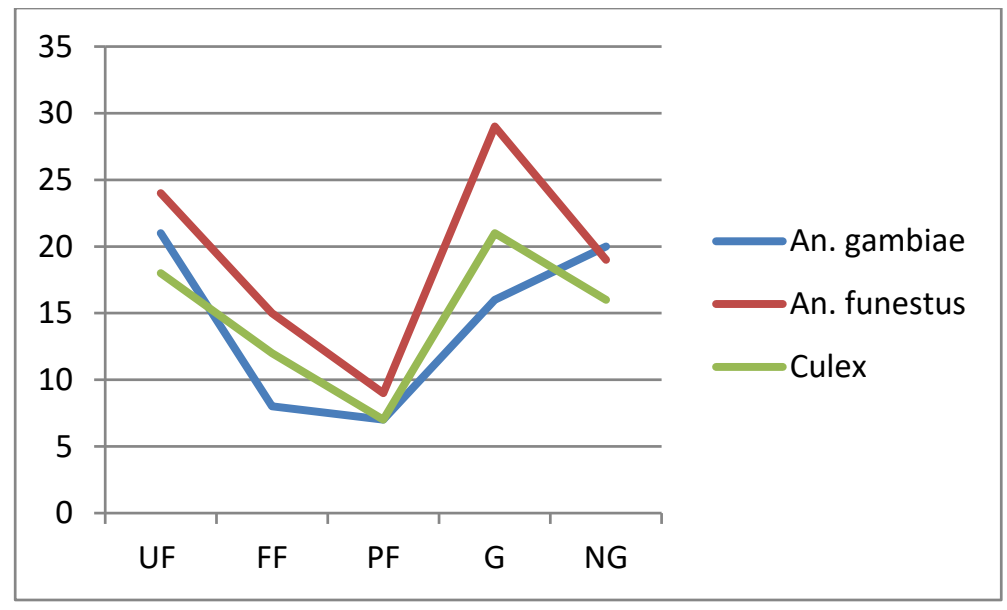

Figure 3 Physical Characteristics of Mosquito species Identified In Ogbakuba Community

\section{Discussion}

Malaria is widespread in Africa and Asia, and World Health Organization (WHO) in recent report has considered it endemic in 76 countries [20]. This study which involved different age groups in Ogbaru LGA of Anambra State has confirmed an ongoing malaria transmission in the area. Overall prevalence of malaria in the area was found to be 20.10\%, a figure far lower than that (70.8\%) reported by Onyido and his colleagues, [21] in Anambra state. The malaria prevalence from this study is also lower than that of Okeke et al., [22] who recorded a prevalence of $46.30 \%$ in the same state. The result is however similar to $24.49 \%$ and $22 \%$ recorded in 2017 and 2019 respectively by Udujih et al [5, 23]. in Anambra state. This is an indication of a progressive reduction in malaria prevalence as reflected also in the Nigeria Malaria Indicator Survey, where RDT prevalence of 52\% was recorded in 2010 and 45\% recorded in 2015 [24, 25]. Also, according to the latest World malaria report, released in December 2019, there were 228 million cases of malaria in 2018, compared to 231 million cases in 2017 and the estimated number of malaria deaths stood at 405,000 in 2018, compared with 416,000 deaths in 2017.

Malaria prevalence in the present study however, varied between the two communities in the local government area. Ogbakuba community recorded a higher prevalence of $24.4 \%$ than Odekpe which had a prevalence of $16 \%$. Onyido et al., [21] also recorded variations in malaria prevalence in different communities in Ihiala Local Government of Anambra State. These variations could be attributed to factors like population cluster, proximity to water bodies (which act as 
breeding sites of mosquito vectors), poor housing system, (which increases indoor biting rate) and use or not use of Insecticide treated bed net.

This study observed higher malaria prevalence in females than in males. However, this must have occurred out of chance as the observed difference was statistically insignificant $(\mathrm{P}>0.05)$.

Overall, age-related malaria prevalence was highest (61.0\%) among those aged between 1 to 7 years. Prevalence of malaria in this study was higher among the children than the adults. This is in line with a 2010 hospital-based study conducted in Gboko Benue State, where Houmsou et al., [26] observed highest malaria prevalence in patients of the age groups 1-10 and 61-70 years. It has been established that children under 5 years of age are particularly susceptible to malaria infection in areas with high malaria transmission and more than $70 \%$ of all malaria deaths occur in this age group [11]. According to the United States Embassy in Nigeria, (2016). Nigeria malaria fact Sheet. (online) Available at:<http://nigeria.usembassy.gov (Accessed 12 march 2019), malaria accounts for $60 \%$ of outpatient visits, 30\% of hospitalizations among children under five years of age in Nigeria and contributes to an estimated $11 \%$ of maternal mortality.

Ogbakuba community had a higher intensity of malaria parasitaemia in this study. This community is in a more rural setting compared with Odekpe which is a semi-urban community. Malaria is normally considered mainly a problem of the rural poor, even though it has been a concern in urban settings for centuries. However, evidence now suggests that economic development and various environmental changes during the twentieth century have reduced the incidence of malaria in urban contexts [27]. Similarly, some studies have suggested lower malaria risk in urban areas compared with neighboring rural areas [28], although the unresolved question of what constitutes an urban versus a rural area in some settings makes comparisons difficult [29].

Only Anopheles and Culex mosquitoes were identified in the present study and both have been reported in different parts of Nigeria by different researchers. Anopheles gambiae sl and An. funestus made up $72 \%$ of the total mosquito population against $28 \%$ by the Culex species. This is in agreement with the findings of Oduola et al., [30] and Bunza et al., [31] who reported Anopheles species to be more dominant in Kwara and Kastina States. However, Okonkwo et al., [32] reported Culex species to be more dominant in Oba, Idemili South of Anambra State. All the mosquitoes in this study were caught inside the houses confirming their anthropophagic, endophagic and endophilic feeding habits. The results of the blood meal and abdominal condition analysis are also a strong evidence of a continuous human-vector contact, on-going disease transmission and a sustained reproduction of the vectors in the area.

All the mosquitoes encountered in this study are potential vectors of different mosquito-borne diseases. Apart from constituting a serious nuisance to humans, Culex species also transmit diseases such as Japanese and Saint Louis encephalitis, Rift valley fever, West Nile Virus and lymphatic filariasis [33]. Apart from malaria, Anopheles mosquitoes are also known to transmit Wuchereri banchrofti (filarial worm); the Timorese filaria, Brugia timori and several arboviruses. Co-endemicity of malaria and lymphatic filariasis has been reported in Anambra state by FMHN [34, 35]. The number of Culex mosquitoes identified in the study areas suggests that there is urbanization of the area as these mosquitoes have a predilection for urban environment. Again, urbanization implies that there is an increasing human population in the areas which is increasing the number of people that will be susceptible to malaria, filariasis and other Culex and Anopheles borne diseases in the areas.

\section{Conclusion}

The findings of this study have shown that there is ongoing transmission of malaria in the area. From the entomological aspect, there is also the possibility of an ongoing transmission of Bancroftian filariasis and other mosquito-borne diseases in the study area. It is therefore necessary to design further studies that would explore the interactions of mosquito species and the diseases they transmit in co-endemic communities as well as effective methods for their control.

\section{Compliance with ethical standards}

\section{Acknowledgments}

We acknowledge and appreciate TETFUND for their sponsorship of this research, Imo State University management and the IBR Committee for the opportunity given to us to embark on this research.

\section{Disclosure of conflict of interest}


There is no conflict of interest among the authors

\section{Statement of informed consent}

Informed consent was obtained from all individual participants included in this study and ethical approval was received from Anambra State ministry of health before the study commenced.

\section{References}

[1] Aribodor, D.N., Njoku, O.O., Eneanya, C.I. and Onyali I.O . Studies on prevalence of malaria and management practices of the Azia community, Ihiala L.G.A., Anambra State, South- East Nigeria. Nigerian Journal of Parasitolology, 2003; 24: 33-38.

[2] Ukpai O.M. and Ajoku E.I. The prevalence of malaria in Okigwe and Owerri areas of Imo state. Nigerian Journal of Parasitology. 2001; 22:43-48.

[3] Sabina, K., Prevalence and Epidemiology of malaria in Nigeria: A Review, International Journal of Research in Pharmacy and Biosciences2017; 4(8):pp.10 -12.

[4] Ukaegbu, C.O., Nnachi, A.U., Mawak, J.D., Igwe, C.C. Incidence of Concurrent Malaria and Typhoid fever Infections in Febrile patients inJos, Plateau state Nigeria. International Journal of Scientific and Technology Research2014; 3(4): pp.157-161.

[5] Udujih, H.I., Amaechi A.A., Nwoke, B.E. B., Uduji, O.G., and Iwuala, C.C. Studies on Malaria and Insecticide Treated Bednet Compliance among Primary School Aged Children in Anambra State, Nigeria International Journal of Science and Research methodology, 2017; 8(1):pp 43 - 52.

[6] Mockenhaupt, F. Erhardt, S., Burkhardt, J., Bosmotive S., Larea, S., Anemana, S., Otchwemah R., Crammer, manifestation and outcome of severe malaria in children in Northern Ghana. American Journal of Tropical Medicine and Hygiene, 2014; 71(2):Pp.167 - 172.

[7] Onwuemele, A. An assessment of the spatial pattern of malaria infection in Nigeria. International Journal of Medicine and Medical Sciences, 2014; 6(2):80-86.

[8] Nworgu, O.C. and Orajiakba, B. N. Prevalence of malaria in Children 1-10years in Communities in Awka North L.G.A Anambra State South East Nigeria. International Multidiscipinary Journal, Ethiopia, 2011; 5(5):pp.264-281.

[9] Olowe, O.A., Olowe, R.A. and Awa O.A. The burden of malaria with historical perspective in Nigerian concept and world view. El Mednifico Journal 2014; 2(3):266-272.

[10] National Population Commission (NPC) (Nigeria) and ICF Nigeria Demographic and Health Survey 2018. Key Indicator Report. Abuja, Nigeria and Rockville, Maryland, USA: NPC and ICF 2019.

[11] Tinashe, A. T., Alinune, N. K., Robert S. M., Henk, V. B., Michele, V. V. and Kamija, S. P. Prevention Efforts for malaria. Current Tropical medicine reports, 2018; 5(1):41-50.

[12] Noor, A. M., Kiru, V. C., Brooke, S. J. and snow, R. W The use of insecticide treated net by age: implications for universal coverage in Africa. BMC Public Health2009; 9(1):369.

[13] Ruhago, G. M., Mujinja, P. G. and Norheim, O. F. Equity implications of coverages and use of insecticide treated nets distributed for free or with co-payment in two districts in Tanzania: a cross-sectional comparative household survey. International Journal of Equity Health. 2011; 10(1):29.

[14] Coleman, M., Hemingway, J., Gleava, K. A., Wiebe, A., Gethin, P. W. and Moyes, C. L. Developing global maps of insecticides resistance risk to improve vector control. Malaria Journal. 2017;16(86);(https://doi.org/10.1186/s12936-017-1733-z)

[15] Federal Ministry of Health, Nigeria master plan for neglected tropical diseases (NTDs) 2013 -2017. Abuja: Federal Ministry of Health 1427. 2013b.

[16] Cheesebrough, M District Laboratory Practice in Tropical Countries.Bulterworth-Heinemann Ltd., Oxford, UK, (2nd edition). 2005.

[17] Harrison J.E., Mathenge E.M., MisianiG.O., Mukabana, W.R.,and Day J.F. A simple method for sampling indoorresting malaria mosquitoes Anopheles gambiae and Anopheles funestus(Diptera:Culicidae) in Africa. Journal Of Medical Entomology2006; 43(3):473-479. 
[18] Gillies M.T. and Coetzee M. Supplement to the Anophelinae of Africa South of Sahara. Johannesburg publications of the South African Institute For Medical Research1987; 55:1-143

[19] World Health Organization Methods and Techniques: Manual on Practical entomology in Malaria Part II. World Health Organization Offset Publication, Geneva 13. 1975.

[20] World Health Organisation World malaria report: World Health Organization (WHO) press, Geneva. 2017.

[21] Onyido, A.E., Obinatu, S.C., Umeanato, P.U., Obiukwu, M.O. and Egbuche, M.C. Malaria prevalence and mosquito vector Abundance in Uli town, Ihiala local government area, Anambra state, Nigeria. African Journal Of Biomedical Research, 2011; 14:175-182.

[22] Okeke, O.P., Imaukwu, C.A., Eyo, J.E. and Okeafor, F.C. Prevalence of malaria infection in children in Anambra state Nigeria after change of policy from presumptive/clinical to confirmed diagnosis.African Journal Online2016; 13 (1);2385-2391

[23] Udujih, H.I., Amaechi A.A., Nwoke, B.E. B.,Ajero, C.M.U.,Udujih, O.G., and Iwuala, C.C. Studies on Malaria, BancroftianFilariasis and Insecticide Treated Bed Nets in MmiataAnam, Anambra West Local Government Area, Nigeria. International Journal of Current Microbiology and Applied Sciences2019; 8(10).

[24] Nigeria Malaria Indicator Survey. 2010 Atlas of key indicator.

[25] Nigeria Malaria Indicator Survey. 2015 Atlas of key indicator.

[26] Houmsou, R.S., Amuta, E.U., Sar, T.T. and Adagba A.H Malaria infection among patients attending semi-urban based hospital and performance of HRP-2PF rapid diagnostic test (RDT) in screening clinical cases of Plasmodium falciparium malaria. 2010.

[27] Tatem, A.J., Gething, P.W., Smith, D.L., Hay, S.I., Urbanization and the global malaria recession.Malaria Journal 2013; $12: 1-10$.

[28] Omumbo, J.A., Guerra, C.A., Hay, S.I., Snow, R.W., 2005. .The influence of urbanisation on measures of Plasmodium falciparum infection prevalence in east Africa.Acta Trop 93: 11-21. Available at: http://www.pubmedcentral.nih.gov/articlerender .fcgi?artid=3191363\&tool=pmcentrez\&rendertype=abstract

[29] Willson, M. L., Krogstad, D. J., Arinaitwe, E., Arevalo-Herrera, M., Cherry L., Ndiaye, D., Mathanga, D.P. and Alex E Urban Malaria: Understanding its Epidemiology, Ecology, and Transmission across Seven Diverse ICEMR Network Sites. American Journal of Tropical Medicine and Hygiene, 2015; 93(3);2015, 110-123 doi:10.4269/ajtmh.14-0834

[30] Oduola, A.O., Adelaya, O.J., Aiyegbusi, Z.O., Tola, M., Obembe, A., Ande, A.T. and Awolola, S. Dynamics of Anopheline vector species composition and reported malaria cases during rain and dry seasons in two selected communities of Kwara State. Nigeria Journal of Parasitology 2016; 37(2).

[31] Bunza, M.D., Suleiman, A.A., Yusuf, A.M. and Bala, A. Relative abundance of mosquito species in Kastina metropolis Nigeria.Nigeria Journal of Parasitology2010; 31(2):73-78.

[32] Okonkwo, N.J., Obiechina, I.O., Ugba, C.N., Irikannu, K.C., Obianumba, S.N., Okoye-Uzochukwu, C.I., Iwuora, O.I. and Chinweke, J.O. Mosquito species composition in Oba, Idemili South local government area of Anambra state.Reseacher 2014; 6(8):51-56.

[33] Goddard, L.B., Roth, A.E., Reisen, W.K. and Scott, T.W Vector competence of California mosquitoes for West Nile virus. Emerging Infectious Diseases. 2002; 8(12):1385.

[34] Federal Ministry of Health 2013a.Guidelines for malaria- lymphatic filariasis co-implementation in Nigeria.

[35] Federal Ministry of Health Nigeria 2015. Neglected Tropical Diseases Nigeria multi-year master plan 2015-2020 